\title{
Filial piety and loyalty: Two types of social identification in Confucianism ${ }^{1}$
}

\author{
Kwang-Kuo Hwang \\ Department of Psychology, National Taiwan University, Taiwan
}

\begin{abstract}
The Confucian concepts of filial piety and loyalty are examined in terms of social identity theory in order to illustrate the arrangement of interpersonal relationships between self and others in Confucian culture. Filial piety, the core idea of Confucian ethics for ordinary people, is explained in the context of my previous analysis of the structure of Confucianism (Hwang, 1995). The social consequences of practicing Confucian ethics for ordinary people in the agricultural society of traditional China are illustrated with Fei's (1948) concept of differential structure and F. L. K. Hsu's (1971) psychosociogram. The concept of loyalty is contrasted with filial piety with reference to the optimal distinctiveness theory. Empirical studies are cited to illuminate the psychological implications of holding filial attitudes and of the modification of filiaty under the impact of modernization. Finally, suggestions for future research are offered based on current analysis of issues related to this topic.
\end{abstract}

In my article "Face and favor: the Chinese power Game" (1987) I constructed a theoretical model to illustrate social interactions in Chinese society. In Chapter 6 of my book Knowledge and Action (1995), I analyzed Confucianism with reference to that model. The goal of this article is to explore the Confucian concepts of filial piety and loyalty in terms of social identification theory in order to distinguish the two types of arrangements for interpersonal relationships between self and other in Confucian culture. Reinterpreting Confucianism from the perspective of social psychology may enable psychologists to construct a series of theoretical models to describe various aspects of Chinese social behavior, and to conduct empirical research in Confucian societies.

First, I use anthropologist Grace G. Harris' (1989) distinctions between the three concepts of individual, self, and person to explain how the Confucian proposition of self and social relationships reflects the Chinese concept of personhood. Second, I present Confucian teachings on the ideal arrangement of interpersonal relationships for ordinary people and for scholars. Analysis focuses on the Confucian concepts of filial piety and loyalty, the cores of ethics for these two categories of person. I adopt social identity theory and the optimal distinctiveness theory to illustrate the two types of social identification implied in the Confucian concepts of filial piety and loyalty. In the final section, I review empirical research on related topics to examine the psychological consequences of holding filial attitudes, and their modification under the impact of Western influences. Suggestions for

Address correspondence to Kwang-Kuo Hwang, Dept. of Psychology, National Taiwan University, Taipei 10764, Taiwan. E-mail: hwangKK@ms.cc.ntu.edu.tw 
future research in this field are offered with respect to the theoretical analysis presented in this article.

\section{The concepts of individual, self, and person}

In an illuminating article, Harris (1989) pointed out that though the concepts of individual, self, and person are frequently used interchangeably by social scientists, the meanings of these three concepts differ significantly. Individual is a biologistic concept, defining human beings as creatures like any other living animal in the world. Person is a sociologistic concept treating human beings as agents in society who take a particular position in the social order and develop a series of actions to achieve personal goals.

In order to view a person as an agent in society, the ways in which the individual follows a certain moral order, takes action, or reacts to others' actions in systems of social relationships should be investigated. From the perspective of a given society, all actions and claims made in support of its sociomoral order are consequences of public construction. Persons who participate in social interaction will perform such a construction with reference to the cultural logic, rules, and values, as well as to their own recognization of factuality. They analyze, label, and interpret each others' actions, thereby creating a stream of public discourse on the causes of action.

Anthropologists study accounts of personhood and the nature of agentive capacities in various cultures by examining the culture's structures or processes. The structural approach entails listing the array of approved social types in a given society. Because social validation is a precondition for social value, the process approach studies the life cycles of various social types in an attempt to understand the agentive capacities being endowed to or withheld from individuals when they enter or leave a particular social type.

Self is a psychologistic concept defining human beings as the locus of experience, including the most important aspect of experiencing oneself as a particular identity. Western psychologists usually assume that an individual's competence in reflexive awareness creates a duality of self. The self as a subject integrates behavior and makes one distinctive from others, resulting in a sense of self-identity. The self as an object of awareness enables one to examine one's differences with other objects in the world, and to view oneself as a unique whole with a sense of personal identity.

Every culture has dominant ideas about the ontology of self: birth, age, disease, end of physical life, the relationship between self and morality, and the relationships between self and others. All these ideas and relationships constitute the concept of personhood in the culture. As a carrier of culture, the self is the meeting point between the individual and the social world. Each person lives in a variety of sociocultural contexts. Each of these contexts makes claims on the person by providing a framework of ideas and practices about "good" or "bad" persons (Markus and Kitayama, 1994). As a result, individuals acquire various (sometimes conflicting) understandings of how to be a person. The self is an integrated locus functioning as the individuated interpretive framework for shaping one's thinking, action, motivation, and emotional reactions.

The connections between culture and self have been studied by many social scientists. The most promising area of research at the cultural level is that of collectivism-individualism. The corresponding theoretical analyses at the psychological level include self-contained and ensembled individualism (Sampson, 1988), independent self and interdependent self (Markus and Kitayama, 1991), and ideocentrism and allocentrism (Triandis et al., 1985). 
These approaches represent a Western way of thinking. One empirical study even ranked cultures along an individualism-collectivism continuum (Hofstede, 1980). Cultures located at the individualist pole were those of North America, and northern and western Europe, all of which originate from the same Christian civilization. Most Asian, African, and Latin American cultures were distributed along the collectivist pole of the continuum. The obvious question that emerges is: Are these collectivist countries homogenous in cultural origin? Models which can not discriminate among diverse collectivist cultures are clearly inadequate.

Some researchers have argued (Hofstede, 1980) that collectivism-individualism is just one dimension differentiating cultures, and a better description of cultures may be obtained if dimensions such as power distance, masculinity, and uncertainty avoidance are taken into consideration. Although this reductionistic approach may increase understanding of the individualistic cultures of the Western world, it still does not improve understanding of collectivist cultures.

Human beings live in their own webs of significance, which are woven with reference to their own cultural traditions (Geertz, 1973). From the perspective of cultural psychology, social discourse on actions in one's own culture necessarily has one's cultural structure of meaning (Shweder, 1991; Shweder \& Sullivan, 1993). Additionally, the core cultural ideas that profoundly influence people's ways of thinking also have that culture's structure of meaning. If we compare cultures by reducing them to a few dimensions, the major webs of significance in each culture are torn to pieces.

\section{The Confucian concept of person}

In The Golden Mean Mencius said, "Humanity [benevolence] comprehends the whole person." This statement illustrates the Confucian concept of person. As an agency of action, a person should follow the Way of Humanity (rendao); this is the prerequisite for being a person. The reason why Mencius made this statement is closely related to his views on the origin of life. During the Spring and Autumn period, the Chinese generally believed that everything in the universe was formed by two opposing yet complementary vital forces (qi): yin and yang.

There was something undefined and yet complete in it, born before Heaven and Earth. Silent and boundless, standing alone without change, yet pervading all without fail. It may be regarded as the Mother of the world. I do not know its name; I term it tao. (Lao Tzu, Tao Te Ching: Chapter 24)

When Lao Tzu was contemplating the ontology of the universe, he believed there existed a fundamental force nurturing and moving everything in the world. Because such a fundamental force could not be adequately labeled, he arbitrarily called it tao (way or path).

Tao gave birth to one, one gave birth to two, two gave birth to three, and three gave birth to myriad things. All things carry the yin on their backs and hold the yang in their embrace, deriving their vital harmony from the proper blending of these two vital forces.

Tao is the foundation of everything in the universe, not a particular being. As the supporting force behind everything, tao is not a state of nothingness. It is the dialectic unification of two opposing yet complementary components: yin and yang, or being and not being. All things have their own tao, but tao is not equivalent to any of them. The tai chi figure popular in 
East Asian societies is an appropriate symbol for the tao. It represents the primary state, and shows that Heaven and Earth are not separate.

The ancient Chinese conceptualized Heaven and Earth as the parents of all things, and believed their sacred mission was to give birth to myriad things and foster them. They traced the origin of all things through analogy to their understanding of the sexual intercourse of human beings. Arrangement of the social order was inferred in the same way in the I-Ching:

Heaven and Earth exist; all [material] things exist. After all [material] things existed, there came male and female. From the existence of male and female there came husband and wife. From husband and wife there came father and son. From father and son there came ruler and minister. From ruler and minister there came high and low. When [the distinction of] high and low existed, the arrangements of propriety and righteousness came into existence. (I-Ching: The Great Appendix, Section 1)

This paragraph clearly illustrates Confucian reasoning in constructing the Way of Humanity through an understanding of the Way of Heaven. Human beings are conceptualized as one of the myriad things in the world. The universe was composed of Heaven and Earth, corresponding to yang and yin. When males and females came into existence creating a social world, their unification gave birth to a second generation, providing grounds for constructing social relationships between father and son, and sovereign and subordinates. Arrangement of social relationships between self and others (the Way of Humanity) corresponds to the Way of Heaven. Only individuals who follow the Way of Humanity are qualified to be persons.

\section{Ethics for ordinary people}

In my book Knowledge and Action (Hwang, 1995), I subdivided the ethical arrangements for interpersonal relationships proposed by the Way of Humanity into two categories: ethics for ordinary people, and ethics for scholars. The former category, which should be followed by everyone including scholars, is best described by the following propositions in The Golden Mean:

Benevolence is the characteristic attribute of personhood. The first priority of its expression is showing affection to those closely related to us. Righteousness means appropriateness; respecting the superior is its most important rule. Loving others according to who they are, and respecting superiors according to their ranks gives rise to the forms and distinctions of propriety (li) in social life. Unless social inequities have a true moral basis, government of the people is an impossibility. (Chapter 20)

These statements illustrate the crucial relationship among the concepts of benevolence, righteousness, and propriety. Confucius advised that social interaction should begin with an assessment of the role relationship between oneself and others along two social dimensions: intimacy/distance and superiority/inferiority. Behavior that favors people with whom one has a close relationship can be termed benevolence (ren); respecting those for whom respect is required by the relationship is called righteousness ( $y i)$; and acting according to previously established rites or social norms is called propriety $(\mathrm{li})$.

The concept of justice in human society is divided into two categories by Western social psychologists: procedural justice and distributive justice. Procedural justice refers to the 
types of procedures that should be used by members of a group to determine methods of resource distribution. Distributive justice is the particular method of resource distribution that is accepted by group members (Leventhal, 1976, 1980).

Confucian ethics for ordinary people can be interpreted in terms of Western justice theory (Hwang, 1995). Confucius advocated that procedural justice in social interaction should follow the principle of respecting the superior. The role of the resource allocator should be played by the person who occupies the superior position. In choosing an appropriate method for distributive justice, the resource allocator should follow the principle of favoring the intimate. Furthermore, from the Confucian perspective, it is righteous to make these decisions in this way.

The theoretical model of Confucian ethics for ordinary people is a template for ethical arrangements in interpersonal relationships. According to the Confucian perspective, it is righteous to decide who has the power of decision making by the principle of respecting the superior; it is also righteous for the resource allocator to distribute resources by the principle of favoring the intimate. It should be pointed out that the Confucian concept of $y i$ (righteousness) is frequently translated into English as justice. However, $y i$ is completely different from the concept of universal justice in Western culture (Rawls, 1971). Yi is generally used in connection with other Chinese characters like ren-yi (benevolent righteousness or benevolent justice) or qing-yi (affective righteousness or affective justice).

In my earlier article "Face and favor: the Chinese power game" (Hwang, 1987), I diagrammed the dynamics of Chinese resource allocation. Confucian ethics for ordinary people can be mapped into this model (Figure 1). The expressive component in the relationship (guanxi) corresponds to the concept of ren. $\mathrm{Yi}$ is to choose an appropriate rule for exchange by considering the expressive component (or affection) between the actors. After careful consideration, the final behavior should follow the social norm of politeness (li).

In Figure 1, a diagonal bisects the rectangle denoting guanxi (interpersonal relationship). The shaded section represents the instrumental component, and the white portion represents the expressive component of the relationship. Instrumental refers to the fact that as biological organisms, people have a variety of innate desires, and they must interact with others in an instrumental manner to obtain the resources required to satisfy these desires. The expressive component denotes interpersonal affection between two parties. The instrumental component mingles with the expressive component in all interpersonal relationships. There are three types of interpersonal relationships: expressive ties describe relationships within the family, mixed ties include relationships with acquaintances outside the immediate family, and instrumental ties are established between oneself and a stranger simply for the purpose of acquiring a particular resource.

Expressive and mixed ties are separated by a solid line, implying a relatively strong psychological boundary between them. It is very difficult for an outsider to become a family member. Instrumental ties are separated from mixed ties by a dotted line, implying that the process of la guanxi (seeking guanxi) may enable a person with instrumental ties to penetrate the relatively weak psychological boundary and transform the relationship into a mixed tie.

\section{The five cardinal rules and the principle of respecting the superior}

Emphasizing the principle of respecting the superior in procedural justice, and the principle of favoring the intimate in distributive justice constitutes the formal structure of Confucian 
Psychological process of resource allocator

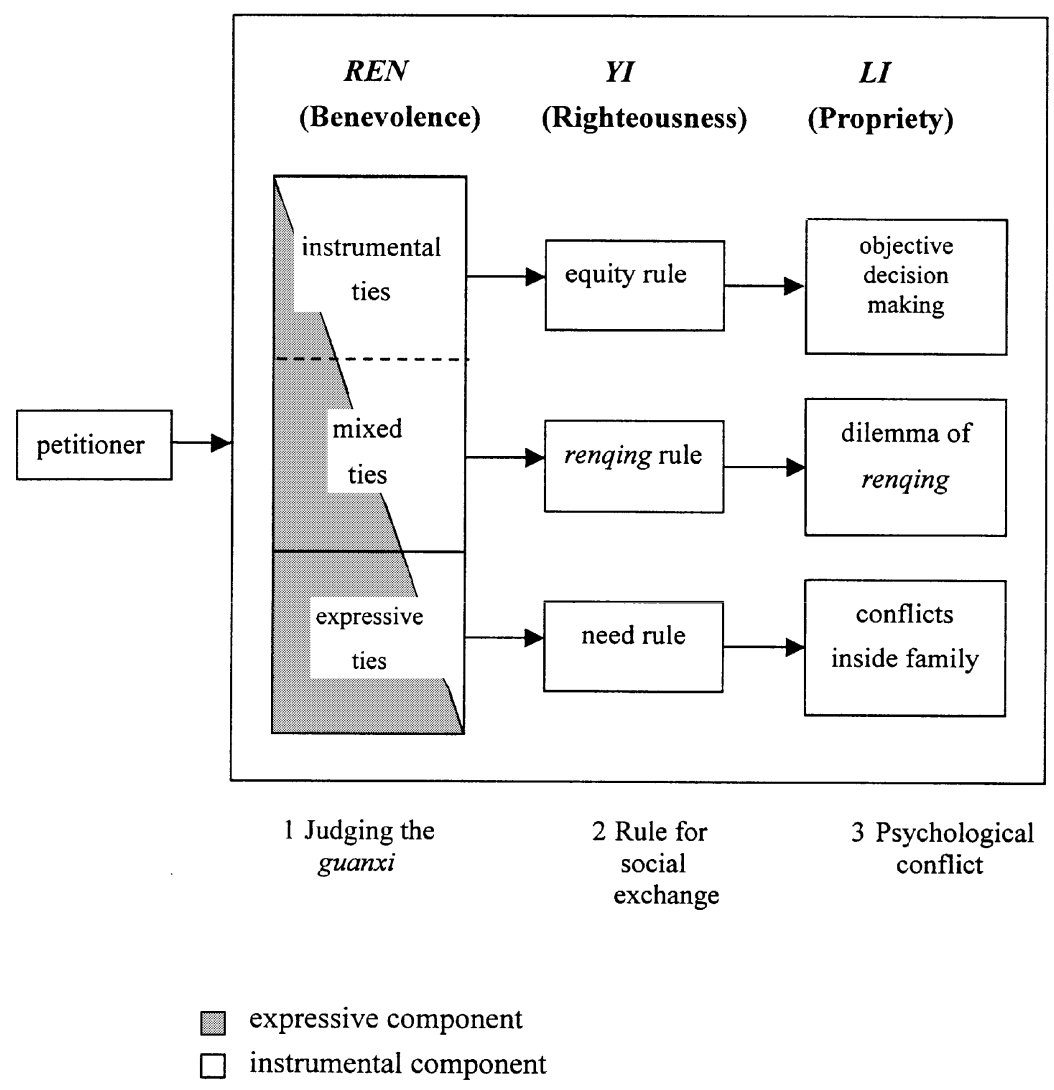

Figure 1. Confucian ethical system of benevolence-righteousness-propriety for ordinary people (adapted from Hwang, 1995, p. 233).

ethics for ordinary people. While this formal structure is manifest in many types of interpersonal relationships, Confucians made additional specific ethical demands on particular relationships. Confucians conceived five cardinal rules for the five major dyadic relationships in Chinese society, proposing that social interaction between members of each pair should proceed according to the Way of Humanity. Each of the roles in these five relationships is distinct, indicating that the core values emphasized in each are also different:

Between father and son, there should be affection; between sovereign and subordinate, righteousness; between husband and wife, attention to their separate functions; between elder brother and younger, a proper order; and between friends, friendship. (The Works of Mencius, Chapter 3A: Duke Wen of Teng)

Three of these rules were designed for regulating interpersonal relationships within the family (expressive ties). The other two are for mixed ties - friends and sovereign/ subordinate. It should also be noted that, except for the relationship between friends, the relationships are all vertical ones between superiors and inferiors. 
What are the things which humans consider righteous $(y i)$ ? Kindness on the part of the father, and filial duty on that of the son; gentleness on the part of the elder brother, and obedience on that of the younger; righteousness on the part of the husband, and submission on that of the wife; kindness on the part of the elders, and deference on that of juniors; benevolence on the part of the ruler, and loyalty on that of the minister. These are the ten things which humans consider to be right. (Li Chi, Chapter 9: Li Yun)

The passage above, which does not include a reference to relationships between friends, promotes the idea that social interaction should follow the principle of respecting the superior. In accordance with the idea of "the ten things of righteousness ( $y i)$," persons who assume the roles of father, elder brother, husband, elders, or ruler should make decisions in line with the principles of kindness, gentleness, righteousness, kindness, and benevolence respectively. And for those who assume the roles of son, younger brother, wife, juniors, or minister, the principles of filial duty, obedience, submission, deference, loyalty and obedience to the instructions of the former group apply.

\title{
Filial piety and the family as one body
}

The reason Confucians proposed the "ten things" is closely related to their understanding of the origin of individuals' lives. When Confucians were contemplating the ontology of the universe, they did not conceive a transcendent creator as did the Christians. Instead, they recognized a simple fact on the basis of Chinese cosmology: individuals' lives are the continuation of their parents' physical lives. Confucian advocacy of filial piety is premised upon this indisputable fact.

Our body, with hair and skin, is derived from our parents. One should not hurt one's own body in any situation. This is the starting point of filial piety. (Hsiao Ching, Chapter 1: The Starting Point and the Principles)

The same idea was repeatedly elaborated in classical Confucian works. For example, in $\mathrm{Li}$ Chi:

\begin{abstract}
Among the myriad things created by Heaven and nurtured by Earth, human beings are the most important. Individuals are given a body by their parents, when they die and return to the earth as a whole body, they are praised as "filial". Taking good care of one's body, and being prudent in personal conduct can be termed "piety". One should not do anything dangerous with one's body as it is inherited from one's parents. One should not forget one's parents when speaking out; if one never says bad words, one need never be insulted by others in anger. If one never does anything dangerous to one's body, and never does anything to cause one's parents to be insulted, one's conduct can be termed filial piety.
\end{abstract}

The Confucian idea of filial piety is constructed on the simple fact that one's body exists solely because of one's parents. In fact, Confucians conceptualized family members as one body.

Father and son are one body; husband and wife, brothers, are all one body. The relationship between father and son is like that between head and feet. Husband and wife are a combination of two separate parts of one body; brothers are the four limbs. (Confucian Rites: Chapter on Mourning Dress) 
Confucians conceptualized the family by analogy to the human body. Each role in the family represents a distinct part of the human body, and together they constitute an inseparable entity. The Confucian configuration of ethical arrangements within a family also corresponds to the body structure. The up-and-down relationship between head and feet refers to the superior and inferior positions of father and son. The Confucian scholar Tung Zhong-Su established the tradition of $y$ ang/superior/male and $y$ in/inferior/female, so the relationship between husband and wife is similarly arranged. Children's bodies originate from their parents', just as the four limbs stem from the body. Children will have their own families, and their children will likewise be oriented towards them. Relationships between senior and junior maintain rank order.

The Confucian ethical system is based not only on the principle of respecting the superior, but also on favoring the intimate. Because family members are conceived of as a whole body, members of a family residing under the same roof have an obligation to share resources with one another. Resource allocators must follow the need rule for social exchange, and do their best to satisfy the needs of their family members. Relationships with friends are different from relationships with family members. Physically, individuals are completely separate entities from their friends, although psychologically they live in a shared social network. Friends may address one another by pseudo-kinship terms in an attempt to maintain psychosocial homeostasis within the network (Hsu, 1971). They should keep their promises to one another and follow the renqing rule by expressing their affection and concern to others in the process of social interaction.

Individuals' relationships with people outside their network of acquaintances are completely different from those within the network. With those outside their network they are separate entities both physically and psychologically. When individuals want to acquire a particular resource from someone with whom they have an instrumental tie, they usually have to pay the cost immediately. This kind of social exchange is seldom discussed in Confucian ethics. Both parties follow the equality rule by utilizing the instrumental rationality of calculation.

\section{Self-cultivation with Tao}

As biological organisms, individuals are born with a variety of desires urging them to acquire various resources to satisfy their needs. Among the pre-Chin Dynasty Confucian scholars, Hsun Tze was the first to emphasize this aspect of human nature:

It is the original nature and tendency of humans to desire gain and to seek to obtain it. ... Now the nature of humans is that when they are hungry, they desire repletion; when they are cold, they desire warmth; when they labor, they seek rest. These are humans' natural feelings. (The Works of Hsun Tze, Book 23: The Nature of Humans is Evil)

According to Harris' (1989) distinctions, Hsun Tze classified human beings as biological organisms. As such, they could become qualified to be considered a person if they followed the Way of Humanity. Of course, tension always exists between an individual's biological needs and society's ethical demands. To be considered persons, Confucians required individuals "to control their desires and maintain Confucian norms" in daily social interactions. Hsun Tze further explained this point: 
They need to maintain personal control with proper conduct (li) and justice (yi), then good government and order will issue, and actions will accord with virtue.

The original nature of humans today is evil, so they need to undergo the instruction of teachers and laws. Only then will they be upright. They need the rules of proper conduct (li) and justice $(y i)$. Only then will there be good government. But humans today are without good teachers and laws, so they are selfish, vicious, and unrighteous.

They are without the rules of proper conduct and justice (yi), so there is rebellion, disorder, and no good government. In ancient times the sage kings knew that human nature is evil, selfish, vicious, unrighteous, rebellious, and of itself could not bring about good government. For this reason they created the rules of proper conduct $(l i)$ and justice (yi). They established laws and ordinances to force and beautify the natural feelings of humans, thus rectifying them. They trained to obedience and civilized humans' natural feelings, thus guiding them. Then good government arose and humans followed the right way (tao). (The Works of Hsun Tze, Book 23:

The Nature of Man is Evil)

Confucians developed a delicate set of methods for self-cultivation. They advocated that everyone from the emperor to ordinary people maintain the five social relationships by the five cardinal rules. Methods of self-cultivation included diligently learning the Way of Humanity, practicing it earnestly, and having a sense of shame when one's conduct deviated from it.

Love of knowledge is akin to wisdom. Strenuous attention to conduct is akin to benevolence. Sensitivity to shame is akin to courage. When humans understand these methods, they will then understand how to cultivate themselves. (The Golden Mean, Chapter 20)

Confucian education consists mainly of instruction on its ethical system. It is based on practical rather than theoretical reason. Unlike theoretical reason, practical reason is aimed at constructing knowledge on the basis of a person's empirical experience (Hwang, 1993). Confucians paid great attention to the individual's practice of tao. They believed that only firsthand experience of practicing the Way of Humanity constitutes a real understanding of Confucian teachings. Embodying Confucian ethics in one's actions is a lifelong endeavor that should be carried out patiently and enduringly ( $\mathrm{Tu}, 1985)$. This point is elaborated in the following paragraph by Hsun Tze:

Sincerely put forth effort, and you will progress. Study until death and do not stop before, for the art of study occupies the whole of one's life. To arrive at its purpose, you cannot stop for an instant. To do this is to be human; to stop is to be a bird or beast. (The Works of Hsun Tze, Book 1: An Encouragement to Study)

A person who was able to practice the Way of Humanity was praised as jun zi (a true gentleman) by Confucians, while one who was concerned with personal interests and benefits in daily life was labeled xiao ren (small-minded person). The term jun zi (true gentleman) originally denoted a person with the status of nobility. Confucius changed its meaning and used it to denote a person with moral cultivation. Only when a person is able to suppress inborn desires and to arrange relationships with others in accordance with the Way of Humanity is that person qualified to be called jun zi. Likewise, if one acts in accordance with one's own desires or interests, one may be criticized as xiao ren, or even called a beast. 
No matter whether an individual takes the role of a petitioner who has to follow the principle of respecting the superior, or the role of a resource allocator who must follow the principle of favoring the intimate, that person may experience tension between personal desires and socio-ethical demands. Confucian scholars of the Sung Dynasty considered this tension to be the result of conflict between the law of Heaven and human desire, and advocated eliminating desires by following the Law of Heaven.

\section{Social identity theory}

American psychologists have generally conceptualized people as independent entities and construed the variety of an individual's social identities as various aspects of that person's self-concept. In contrast, European psychologists tend to conceptualize social identities as an extension of the individual's self, which is integrated into a social network. As a product of European thinking, social identity theory may be used as a framework for understanding the Confucian principle of eliminating desire by following the Law of Heaven.

The main concepts of social identity theory are represented by the scheme of concentric circles in Figure 2 (Brewer, 1991, p. 476). The self is located at the center, while the outer circles represent the social groups with which one identifies. The concentric circles denote levels of inclusiveness in the various social groups by which individuals define themselves in specific domains. At the center of the concentric circles, personal identity represents characteristics of the individuated self that enable one to differentiate oneself from others. Social identities enable one to classify oneself into inclusive social units, eliminate personal characteristics of self, and transform oneself from "I" to "we." A particular social identity requires one to perceive oneself as a member of a particular social category who can be replaced by any of several others, rather than as a particular person (Turner et al., 1987).

From the perspective of social identity theory, the major goal of Confucian selfcultivation is to socialize individuals to suppress personal identity in social interactions, and to eliminate personal desires by following the Way of Humanity proposed by the Law of Heaven. A person should follow the principle of respecting the superior, and wait for the resource allocator, who occupies a higher position, to make decisions. Resource allocators must have the intention of benevolence, and do their best to satisfy the needs of others. As a

(a)

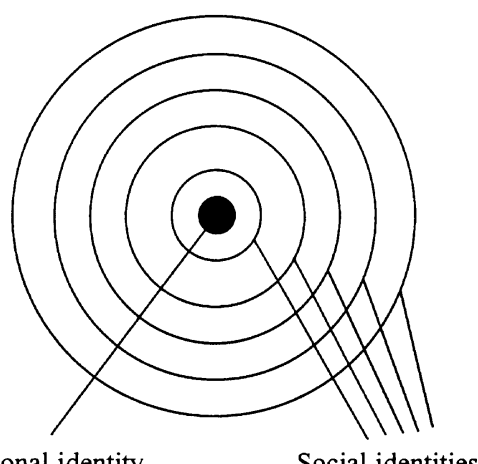

(b)

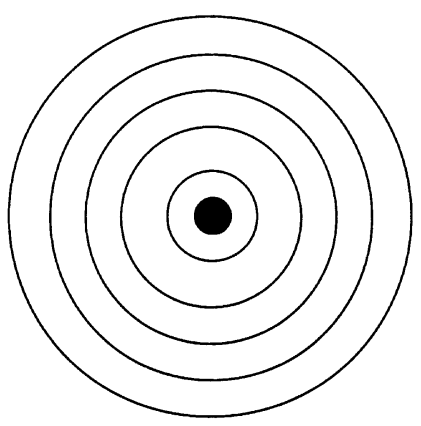

Personal identity

Social identities

Figure 2. (a) Personal and social identities (adapted from Bewer, 1991; p. 476). (b) Fei's hierarchical structure of Chinese society. 
consequence of this social identification, "I" is transformed into "we" and social identity with the group is intensified.

\section{Differential order of Chinese society}

The reason why a particular ideology is widely accepted by the people of a given culture can be traced to the way of life in that particular ecological environment (Berry, 1994). That Chinese social identity predominates over individual identity can be understood not only through evidence of the government's deliberate promotion of Confucian ethics, but also by the people's way of life.

In the agricultural society of traditional China most people were farmers, and stayed in a particular area and functioned in a stable social network. When children were born, parents and relatives in the social network treated them as the continuation of the family. The parents (especially the mother) took care of them, satisfied their needs, and bathed them with benevolence. When children reached the age of five or six years old, parents believed children were able to understand social affairs, began to teach them the norm for being a person (righteousness), and required them to be polite to their seniors (propriety). As the children grew older, adults in the family might teach them various aspects of social intelligence (wisdom), especially keeping promises to friends (trustworthiness). Growing up in this type of cultural milieu, an individual's pattern of social interaction with others in the social network would likely be congruent with Confucian ethics, even if that person never received any formal education in Confucianism.

In terms of Figure 1, people with whom an individual must interact in daily life in this type of society were family members with expressive ties or acquaintances with mixed ties. A person certainly might have some opportunity to interact with strangers with instrumental ties, but it was nearly impossible for people to become involved in social groups other than their family or clan (Hsu, 1963, 1967). As a consequence, the relationships surrounding an individual were characterized by hierarchical structure of intimacy, as illustrated by the concentric circles in Figure 2.

Individuals in a Western society of individualism are akin to wooden sticks which may be bound together by their social organization just like a bundle of sticks. The structure of Chinese society is like ripples caused by throwing a stone into a pond. Everybody is situated at the center of water rings which are extended to reach an edge of one's social influence. No matter when and where one finds oneself, one is always situated at the center of the flexible social network. This is not individualism, this is egoism. The Chinese are very egocentric, and all of their values are oriented to serve their own various needs. (Fei, 1948, pp. 24-27)

\section{Psychosociogram and psychosocial homeostasis}

Although Fei's concept of differential order has been widely cited by psychologists to describe characteristics of Chinese society, it is only a rough analogy. Francis Hsu's (1971) psychosociogram depicts socio-psychological character with greater precision. It consists of seven irregular, concentric layers: unconscious, pre-conscious, unexpressed conscious, expressible conscious, intimate society and culture, operative society and culture, wider society and culture, and outer world (see Figure 3). Layer 4 in Figure 3 is labeled expressible conscious. It contains the feelings and ideas which individuals communicate to fellow human beings: love, hatred, greed, vision, and knowledge of the ways of doing things according to 


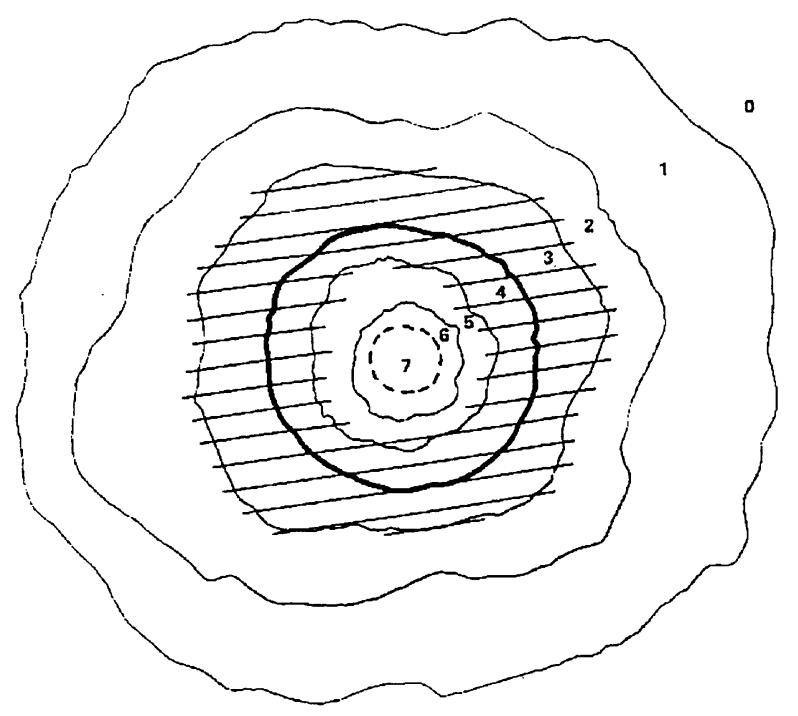

7 Unconscious

6 Pre-conscious

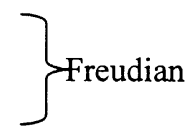

5 Unexpressed conscious

4 Expressible conscious

3 Intimate society and culture

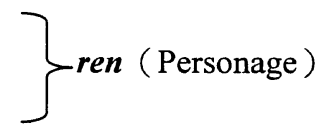

2 Operative society and culture

1 Wide society and culture

0 Outer world

Figure 3. Psychosociogram of Man (adapted from Hsu, 1971; p. 25).

the moral, social, and technical standards of the culture. Layer 3 consists of significant others with whom the individual has intimate relationships, pets, cultural usages, and material collections. The individual's relationship with human beings, animals, artifacts, and cultural rules in this layer tend to be "a matter of feeling rather than of usefulness" (Hsu, 1971, p. 26). In contrast, the individual may establish only formal role relationships with those inhabiting Layer 2 by considering "their usefulness to him rather than his feeling toward them" (ibid.).

Hsu called the shaded area covering Layers 3 and 4 and partially covering Layers 2 and 5 ren, and claimed that this Chinese word may be roughly translated into English as personage. The Chinese conception of ren is based on the individual's transactions with fellow human beings. It implies that one may maintain a satisfactory level of psyche and interpersonal equilibrium within the shaded area only by endeavoring to be ren (zuo ren) and learning to be ren (xие zио ren). The process of maintaining a constant state by fitting one's external behavior to the interpersonal standards of society and culture is defined as psychosocial homeostasis (Hsu, 1971). 
From the perspective of my theoretical model in "Face and Favor" (figure 1), ren is the expressive component contained in the resource allocator's guanxi with others, usefulness denotes the instrumental component of guanxi in the dyad of interaction. The intimate society of Figure 3's Layer 3 consists of expressive ties and mixed ties, while the operative society of Layer 2 is constituted by one's role relationships with a person of instrumental ties. Choosing appropriate rules of social exchange to interact with others may contribute to the maintenance of psychosocial homeostasis. In other words, Hsu's psychosociogram can be reinterpreted with the terminology of social exchange with reference to my theoretical model from "Face and favor." It can also be linked to Confucian traditions through my analysis of the structure of Confucianism.

\section{Ethics for scholars}

The hierarchical structure of traditional Chinese society was formulated when most people lived by following the sociomoral order of Confucian ethics for ordinary people. In addition to ethics for ordinary people, Confucians had a separate set of higher moral standards for scholars. According to Confucian ideals, in order for scholars to occupy a higher position in government, they had to be educated to obtain a determination to practice the Way of Humanity to the best of their capacity. The larger the scope in which a scholar exercised the Way of Humanity, the higher that scholar's moral performance needed to be. Confucians encouraged scholars "to cultivate themselves, to manage their families, to govern the nation, and to bring tranquillity to the world."

Just like the Confucian ethics for ordinary people, the Confucian ethics for scholars can be cast in terms of social identity theory. According to social identity theory, individuals live in social networks of concentric circles. Scholars who occupied a higher social position in government not only exercised the Way of Humanity within their families, but also extended benevolence to larger groups. Scholars were trained to forget themselves in the course of their official duties. By so doing, they could become consciously aware of their social identities.

The most important moral principle for a scholar to follow is loyalty. However, Confucians made a clear distinction between loyalty to the sovereign and loyalty to the Way of Humanity as indicated by filial piety. They endowed scholars with the mission of practicing the Way of Humanity rather than a moral commitment of loyalty to the sovereign. In other words, the Confucian concept of loyalty for scholars differs from the loyalty of filial piety (Hsu, 1983).

In the Warring States period in China, the sovereign of a state held the highest power. According to the Confucian principle of respecting the superior, the sovereign had the highest decision-making power. Confucians believed that once a scholar became an official, the most important way for that scholar to actualize Confucian ideals was to serve the sovereign with the Way of Humanity.

Let the prince be benevolent; all people will be benevolent. Let the prince be righteous; all people will be righteous. Let the prince be correct, and everything will be correct. Once the ruler is rectified, the kingdom will be firmly settled. (The Works of Mencius, Book 4: Li Lau, Part I)

The most important duty for a minister was to rectify what is wrong in the sovereign's mind: 
The way in which a minister serves his prince contemplates simply leading him in the right path, and directing his mind to benevolence. (The Works of Mencius, Book 6: Kao Tze, Part 2)

In Confucian terms, serving the sovereign with the Way of Humanity constitutes loyalty. Benevolent sovereign and loyal minister is certainly one of the ideal relationships advocated by Confucians. However, when a sovereign wants to do something contradictory to the principle of benevolence, what should a loyal minister do? Though Confucians proposed the principle of respecting the superior, and advocated the social relationship of "kind father and filial son," "benevolent sovereign and loyal minister," when the superior violates a moral principle, the subordinate should try to correct him:

In ancient times, if the Son of Heaven had seven ministers to advise him, he would not lose his empire, even if he were imperfect. If a prince had five good men to counsel him, he would not lose his country. If a father had one son to reason with him, he would not be engulfed in moral wrong. Thus, if a father contemplates moral wrong, a son must never fail to warn his father against it, nor must a minister fail to perform a like service for his prince. In short, when there is question of moral wrong, there should be correction. How can you say that filiality consists of simply obeying a father? (Hsiao Ching, Chapter 15: The Duty of Correction)

It should be emphasized that the father/son and sovereign/minister relationships belong to two distinct categories. When the superior in each of these relationships was engaged in morally wrong activities, the subordinate's reaction in making suggestions for correction was also different. Parents are the source of the child's life; the blood relationship between parents and children is unchangeable. Therefore,

If a parent has a fault, [the son] should with bated breath, and bland aspect, and gentle voice, admonish him. ... If the parent be angry and [more] displeased, and beat him till the blood flows, he should not presume to be angry and resentful, he should follow [his remonstrance] with loud crying and tears ... showing an increased degree of reverence, but not abandon his purpose. ( $\mathrm{Li}$ Chi)

However, there are no inseparable relationships between sovereign and minister. There was a time when King Hsun of Chi asked Mencius for advice about the office of high ministers. Mencius distinguished between relationships in which the high ministers are in the nobility and therefore relatives of the prince, and those in which they have different surnames from the prince. For those in the first category who have a blood connection with the prince, if the prince makes serious mistakes and does not respond to their respected admonitions, they should determine their course of action by considering the principle that "the people are the most important element in a nation; the spirits of the land and grain are the next; the sovereign is the lightest" (The Works of Mencius, Book 7: Tsin Sin, Part 2). They should supersede the prince, as he might harm the state.

The high ministers with different surnames from the prince have no inseparable connection to him. If the prince makes mistakes and does not accept their repeated advice, they can just leave the state for another one. If the only emperor is tyrannical and does not practice benevolent government, then powerful chiefs of state should step forward and "punish the tyrant and console the people." For example, in a famous dialogue with Mencius, King Hsun of Chi asked about a case in which a minister put his sovereign, named Chau, to death. Mencius answered: 
He who outrages benevolence is called a robber; he who outrages righteousness is called a ruffian. The robber or ruffian is a mere peasant. I have heard of the cutting of the peasant Chau, but I have not heard of putting a sovereign to death. (The Works of Mencius, Book I: King Hui of Liang, Part 2)

\section{The optimal distinctiveness theory}

Confucian ethics for scholars can be interpreted in terms of the optimal distinctiveness theory, which was derived from the social identity theory. As emphasized by Brewer (1991), a person's social identity is not the same as that person's membership of a social group. The qualification for being a member of a particular group may either be ascribed or achieved, but the social identity in a given situation is always chosen by the individual. One may recognize that one belongs to a variety of social groups, but may select a particular group to identify with at one time, and shift to another in a different social context at another time.

In order to explain the reason why an individual chooses a particular group with which to identify, the optimal distinctiveness theory differentiates two psychological needs: the need for individuated uniqueness, and the need for being included in a group. When an individual identifies with a specific role of a certain group (represented by a point on any circle in Figure 2), the alternative possible identities (indicated by the circle) may serve as a frame of reference for discrimination and social comparison. The sense of distinctiveness emerges from the process of social identification in a particular social context. Instead of identifying with an alternative group, when a person can manifest distinctiveness through identification with a particular social group, it may intensify identification with that group.

Acknowledging the human possibility of becoming good or evil, Confucians encouraged the individual to cultivate the innate moral self. From the perspective of optimal distinctiveness theory, Confucians expected scholars to display the distinctiveness of their moral selves in every action or decision made once they occupied an official post. If a scholar gave advice and the sovereign followed it, the distinctiveness of the scholar's "moral self" was manifest. The scholar's identification with the state was intensified through the successful display of loyalty. In contrast, if the sovereign did not follow the scholar's advice, it was morally acceptable for the scholar to quit the job. If the sovereign was so tyrannical that his atrocities violated the principle of benevolence, scholars could show the distinctiveness of his "moral self" by initiating a revolution to overthrow the tyrant in the name of loyalty to the state and to the people with whom he identified.

"To console the people by punishing the tyrant" is a Confucian ideal. It has rarely happened in real life. On the contrary, in Oriental societies, it is important for individuals to learn the social skill of distinguishing their uniqueness by contributing to group goals. Hinkle \& Brown (1990) pointed out that social identity theory is most applicable to the collectivism of group identity. Their members "feel concerned about their communities and ingroups [and] feel proud of their group's achievements" (Triandis et al., 1988, pp. 325335). On the other hand, individualist cultures "find it completely rational to "do their own thing' and to disregard the needs of their communities, family, or work groups, [and] are proud of their achievements and success in personal competition" (ibid.). When an Oriental society is transformed into a modern one, the tendencies of both collectivism and individualism may be manifest at an individual level as either idiocentric or allocentric personalities. They can also be found at a subcultural level as distinct orientations within 
different social groups. In modern Oriental society, individuals may attempt to show the distinctiveness of their competence rather than their "moral self."

\section{Modernization and the modification of Confucian culture}

In this article, I have analyzed the structure of Confucianism with special attention to the arrangements between self and others in various social relationships. This analysis can be used to examine the extent of change in interpersonal relationships among East Asian people under the impact of Western culture.

Currently, many Confucian societies in East Asia are undergoing rapid cultural change, especially Korea, Taiwan, Hong Kong, Singapore, and several coastal areas of China on the Pacific Rim. The expansion of capitalistic economies has facilitated the emergence of various commercial and industrial organizations. As a result, increasing numbers of people have given up their traditional ways of life and adopted modern ones. New concepts of personhood have arisen. Given this situation, how will the significant features of social relationships among East Asian people influenced by these new concepts change?

\section{Filial piety and authoritarian moralism}

The indigenous concept of filial piety and its derivatives are so specific to Confucian culture that no comparable concepts can be found in other cultures. Several Chinese psychologists have studied the influence of filial piety on Chinese social behavior (Ho, 1996). For example, Lee (1974) delineated five stages of development in filial cognition, Yeh \& Yang $(1989,1990)$ proposed a conceptual framework for analyzing filial behavior, and Ho \& Lee (1974) developed a filial piety scale to measure the traditional filial attitudes rooted in Confucianism.

Performing filial duties toward parents and ancestors was obligatory for a person to maintain psychological homeostasis in traditional Chinese society, but when many Chinese societies all over the world have evolved from agricultural into commercial or industrial ones, will Chinese people insist on their cultural tradition of filial piety? Who tends to insist on the cultural tradition? Will concepts of filial piety be subject to modification? Results of studies of filial piety such as those mentioned above may enable social psychologists to answer these pressing questions.

Ho $(1987,1994,1996)$ argues that authoritarian moralism is a central characteristic of the Chinese pattern of socialization molded by the moral imperative of filial piety. This construct embodies two significant features of Chinese societies: a hierarchical structure of authority ranking in family and other social institutions, and a pervasive tendency to judge other people against moral standards or moral precepts. Using the filial piety scale as an instrument of measurement, Ho's empirical data indicate that filial attitudes tend to be moderately associated with such traditional parental attitudes toward child training as overcontrol, overprotection, harshness, emphasis on proper behavior, neglect, and inhibition of self-expression, independence, and creativity in the child. People holding filial attitudes tend to adopt a passive, uncritical, and uncreative orientation toward learning. They are more inclined to endorse fatalistic, superstitious, and stereotyped beliefs, and are disposed to possess such personality characteristics as authoritarianism, dogmatism, and high conformity. Ho terms this constellation of attributes cognitive conservatism (1996). It is strongly associated with both traditionalism and culturocentrism. Traditionalism consists of 
a past orientation and following in the footsteps of one's forebears, while culturocentrism implies a worldview of believing in the permanence, centrality, and even superiority of one's own culture.

What kinds of people in Chinese society tend to hold these filial attitudes? Ho's data $(1989,1996)$ showed that in both Hong Kong and Taiwan these filial attitudes are more prevalent among people of low socio-economic status. Education has a significant negative relationship with filial attitudes. Women, older people, and people in Taiwan tend to affirm stronger filial attitudes than do men, young people, and people in Hong Kong. Yeung (1989) reported that the filial attitudes of elderly people were positively correlated with higher expectations of social and psychological support from their family members, and negatively correlated with self-reported life satisfaction. Considering all the evidence, it seems plausible that the prevalence of filial piety and its accompanying authoritarian moralism in Chinese societies has diminished as a consequence of modernization and exposure to Western influences.

\section{Familism and emotional interdependence}

Ho's filial piety scale overemphasizes some aspects of authoritarianism. Filial piety does not solely consist of authoritarian moralism. According to the present analysis, in addition to the authoritarian moralism of respecting the superior, filial piety also consists of an affective component emphasizing the intimacy between parents and children. Yeh (1997) and Chu (1997) analyzed responses of 1,863 adults to another filial piety questionnaire in a 1994 Taiwan social survey sponsored by Academia Sinica. Both researchers found that the importance of passive filial piety emphasizing obedience to the authority of parents has decreased to a minimal extent. However, the value of active filial piety supporting a benevolent and affective consideration and care for parents is still sustained or has even strengthened among Taiwanese people.

These research findings can be understood from a broader perspective. In an article entitled "Familism and development", Yang (1988) reviewed a series of studies on the family conducted in Taiwan, Honk Kong, and Mainland China. She examined four aspects of family change: the father/son axis, hierarchical power structure, mutual dependence, and dominance of family interaction. Her results indicated that although the content of Chinese familism has changed, cultural ideas about family are resistant to change. After completing higher education, younger generations are able to find jobs outside of their families and have their own income. As a consequence, parents have decreased power to make decisions about their children's mate selection and money expenditure, and the father/son axis emphasizing submission to authority has weakened. In addition, the separation of residence for younger generations as they reach adulthood, increased employment opportunities for females, and legal protection of women's rights have all weakened the hierarchical relationship between men and women. The separation of family members' residences may decrease the opportunity for personal interaction; however, the likelihood of interpersonal conflict is also reduced.

One of the most enduring aspects of Chinese familism is the mutual interdependence of family members. Most parents do their best to educate and take care of their children, while most children assume the obligations of filial piety, and are willing to repay and support their aging parents. When any family member encounters trouble in life, other family members are obligated to help.

These findings may be reinterpreted with reference to Confucian ethics for ordinary people. As a result of the decentralization of power for controlling resources within the 
family, the principle of respecting one's superior may increasingly be neglected. The principle of favoring the intimate is relatively robust and resistant to change.

\section{Organization-centered loyalty: Suggestions for future research}

Under the influence of traditional cosmology and ontology, many Asians do not conceptualize themselves as independent entities against the world. On the contrary, they consciously live in a network of interpersonal relationships. Relationships with others are characterized along superior/inferior and intimacy/distance dimensions. The self is situated at the center of the network, and is surrounded by dominant relationships with family members (Ho, 1997). In Chinese culture, the personal identity defined by the boundary of one's physical self is identified as the small self, while the social identity defined by sanguineous ties with one's family members is called the great self. Since there is a gradient of expressive component in the sanguineous ties, the boundary of the great self may be extended to even greater ranges. The Chinese tend to address their acquaintances in terms of appellations denoting pseudo-kinship ties once they intend to include someone in their social network.

As East Asian agricultural societies transform into commercial or industrial ones, the importance of different types of relationships may also shift. In modern society when children attain adulthood, they participate in various social groups and establish many instrumental or mixed ties with others. They must adjust their role from home-centered to organization-centered (Hsu, 1971). The values emphasized by these new groups might be particular professional achievements rather than the principle of benevolence advocated by Confucian ethics for scholars. The most important factor determining an individual's strong social identity with a particular group might be the resolution of the conflict between the individual's need for distinctiveness in performance, and the individual's need for inclusiveness in the group. The most significant moral principle for a person to consider when immersed in group identity is loyalty.

Previous sections have shown that the Confucian conceptions of loyalty and filial piety are not equivalent. Since one's parents are the origins of one's life, filial piety toward one's parents should be unconditional (Hwang, 1998). In contrast, the Confucian conception of loyalty contains the idea of liberalism (de Bary, 1983). Loyalty to the state which one identifies is more important than loyalty to the sovereign of the state.

Findings from Western psychology can shed light on this type of loyalty. Hirschman (1970) identified three types of loyal behavior in employees of an organization facing the crisis of decline. Unconscious loyalty results from ignorance of organizational decline due to selective attention or biased perception. Passive loyalty implies a tendency to wait with patience, supporting the organization privately or in public, and believing that the organization will make the right decisions and eventually survive the crisis. Active loyalty advocates voicing concerns and working to ensure the organization's future.

Western psychologists have debated whether loyalty activates or suppresses action on the part of dissatisfied employees; it has been a controversial issue for years (Graham \& Keely, 1992). Confucians stood fast on the former position. However, a major figure of contemporary neo-Confucianism, Professor F. G. Hsu (1983), pointed out that parts of Confucian classics had been altered by anonymous scholars for the pleasure of the Emperor after the Han Dynasty (206BC-AD219). These scholars mixed the connotation of loyalty with that of filial piety, emphasizing the subordinate's personal loyalty to the sovereign, and distorting the original meaning of loyalty in Confucianism. Therefore, Liu (1982) made a 
clear distinction between two types of loyalty. Loyalty to the state was defined as public loyalty. When China evolved a stable political system and unified empire after the Han Dynasty, the relationship between sovereign and minister became that of master and servant. The connotation of loyalty became blind submission to the authority of the ruler, and was termed private loyalty.

It is necessary to make this theoretical distinction between the concepts of loyalty in order to study Chinese organizational behavior. The Confucian concept of loyalty to the social group with which one identifies may have different psychological implications from the concept of loyalty to the leader of an organization. Furthermore, there may even exist a third type of loyalty. When an Oriental society is transformed into a modern one, as is happening with the Westernization of Chinese societies all over the world, traditional conceptualizations may be insufficient. For example, young scholars with a Western-style educational background may take science as a vocation and feel a strong loyalty to that body of knowledge. Instead of identifying with the organization, with which relations might be highly individualized, a person might instead identify with the knowledge of the profession. Though many studies on Chinese organizational behavior have shown that an employee's loyalty to the organization is highly valued by Chinese entrepreneurs (Cheng, 1991; Cheng, 1996; Chou, 1984; Silin, 1976), the meanings of loyalty in Chinese cultural tradition have never been elaborated from the perspective of social psychology. It is expected that this analysis may make a contribution to future research in the field.

\section{Note}

1. This paper was written while the author was supported by a great from National Science Council, Republic of China, NSC 87-2413-H-002-002. The author wishes to express his sincere gratitude to two anonymous reviewers for their constructive comments on earlier versions of the manuscript.

\section{References}

Berry, J. M. (1994). Ecology of individualism and collectivism. In U. Kim, H. C. Triandis, G. Kagitcibas, S. C. Choi, \& G. Yoon (Eds.), Individualism and collectivism: Theory, method, and applications (pp. 77-84). Thousand Oaks, CA: Sage.

Brewer, M. B. (1991). The social self: on being the same and different at the same time. Personality and Social Psychology Bulletin, 17, 475-482.

Cheng, B. S.(1991). Familism and leadership behavior. In H. S. R. Kao \& C. F. Yang (Eds.), Chinese people and Chinese mind: Personality and society [in Chinese] (pp. 365-407). Taipei: Yuan Liu.

Cheng, C. Y. (1996). Organizational loyalty in Chinese business: Structure and process. Unpublished Master's thesis, National Taiwan University.

Chou, Y. H. (1984). A study on Chinese value system and management behaviors in large-scale Taiwanese enterprises. Unpublished doctoral dissertation, National Cheng-Chi University.

Chu, R. L. (1997). Changes of family ethics in Taiwanese society. Paper presented at Second International Conference of Chinese Psychologists. Chinese University of Hong Kong.

de Bary, W. T. (1983). The liberal tradition of China [in Chinese]. (H. Lee, Trans.) Hong Kong: The Chinese University Press.

Fei, S. T. (1948). Rural China [in Chinese]. Shanghai: Observer.

Geertz, C. (1973). The interpretation of cultures. New York: Basic Books.

Graham, J.W., \& Keeley, M. (1992). Hirschman's loyalty construct. Employee Responsibilities and 
Right Journal, 5(2), 191-200.

Harris, C. G. (1989). Concepts of individual, self, and person in description and analysis. American Anthropologist, 91(3), 599-612.

Hinkle, S., \& Brown, R. J. (1990). Intergroup comparisons and social identity: Some links and lacunae. In D. Abates \& M. Hogg (Eds.), Social identity theory: Constructive and critical advances (pp. 4870). New York: Springer-Verlag.

Hirschman, A. O. (1970). Exit, voice and loyalty. Cambridge, MA: Harvard University Press.

Ho, D. Y. F. (1987). Fatherhood in Chinese culture. In M. E. Lamb (Ed.), The father's role: Crosscultural perspectives (pp. 227-245). Hillsdale, NJ: Erlbaum.

Ho, D. Y. F. (1989). Continuity and variation in Chinese patterns of socialization. Journal of Marriage and the Family, 51(1), 149-63.

Ho, D. Y. F. (1994). Filial piety, authoritarian moralism, and cognitive conservatism in Chinese societies. Genetic, Social, and General Psychology Monographs, 120, 347-65.

Ho, D. Y. F. (1996). Filial piety and its psychological consequences. In M. H. Bond (Ed.), The handbook of Chinese psychology (pp. 155-165). Hong Kong: Oxford University Press.

Ho, D. Y. F. (1997). Interpersonal relationship and relationship dominance: an analysis based on methodological relationalism. Asian Journal of Social Psychology, 1 (1), 1-16.

Ho, D. Y. F., \& Lee, L. Y. (1974). Authoritarianism and attitude toward filial piety in Chinese teacher. The Journal of Social Psychology, 92, 305-6.

Hofstede, G. (1980). Culture's consequences: International differences in work-related values. Beverly Hills, CA: Sage.

Hsu, F. G. (1983). The formation and change of Chinese thoughts on filial piety and its related problems in history. In F. G. Hsu (Ed.), Essays on history of Chinese thoughts [in Chinese] (pp. 155-208). Taipei: Student's Bookhouse.

Hsu, F. L. K. (1963). Clan, caste and club. New York: Van Nostrand.

Hsu, F. L. K. (1967). Under the ancestors' shadow: Kinship, personality and social mobility in village China. New York: Doubleday.

Hsu, F. L. K (1971). Psychological homeostasis and ren: Conceptual tools for advancing psychological anthropology. American Anthropologist, 73, 23-44.

Hwang, K. K. (1987). Face and favor: The Chinese power game. American Journal of Sociology, 92(4), 944-974.

Hwang, K. K. (1993). Dao and the transformative power of Confucianism: A theory of East Asian modernization. In W. M. Tu (Ed.), The triadic chord: Confucian ethics, industrial East Asia, and Max Weber (pp. 229-278). Singapore: The Institute of East Asian Philosophies.

Hwang, K. K. (1995). Knowledge and action: A social psychological interpretation of Chinese cultural tradition [in Chinese]. Taipei: Psychological Publishers.

Hwang, K. K. (1998). Two moralities: Reinterpreting the finding of empirical research on moral reasoning in Taiwan. Asian Journal of Social Psychology, 1(3), 211-238.

Lee, B. (1974). A cognitive developmental approach to filiality development. Unpublished Master's thesis, University of Chicago.

Leventhal, G. S. (1976). Fairness in social relationships. In J. Thibaut, J. Spence, \& R. T. Carson (Eds.), Contemporary topics in social psychology (pp. 221-239). Morristown, NJ: General Learning Press.

Leventhal, G. S. (1980). What should be done with equity theory? In K. J. Gergrn, M.S. Greenburg, \& R. H. Wills (Eds.), Social exchange: Advances in theory and research (pp. 27-55). New York: Plenum Press.

Liu, C. Y. (1982). Public and private: ethical implications of loyalty. In C. J. Huang (Ed.), The way of heaven and the way of humanity (pp. 171-207). Taipei: Lien-jin Publisher.

Markus, H. R., \& Kitayama, S. (1991). Culture and the self: implications for cognition, emotion, and motivation. Psychological Review, 98, 224-253.

Markus, H. R., \& Kitayama, S. (1994). The cultural shaping of emotion: a conceptual framework. In S. Kitayama, \& H. Markus (Eds.), Emotion and culture. Washington, DC: APA Books. 
Rawls, J. (1971). A theory of justice. Cambridge, MA: Harvard University Press.

Sampson, E. E. (1988). The debate on individualism: Indigenous psychology of individuals and their role in personal and societal functioning. American Psychologist, 1, 15-22.

Shweder, R. A. (1991). Cultural psychology: what is it. In Thinking through culture: Expeditions in cultural psychology (pp. 73-112). Cambridge, MA: Harvard University Press.

Shweder, R. A., \& Sullivan, M. A. (1993). Cultural psychology: Who needs it. Annual Reviews of Psychology, 44, 497-523.

Silin, R. H.(1976). Leadership and values: The organization of large-scale Taiwanese enterprises. Cambridge, MA: Harvard University Press.

Triandis, H. C., Leung, K., Villareal, M. J., \& Clack, F. L. (1985). Allocentric vs. idiocentric tendencies: convergent and discriminant validation. Journal of Research in Personality, 19, 395415.

Triandis, H. C., Bontempo, R., Villareal, M. J., Asai, M., \& Lucca, N. (1988). Individualism and collectivism: Cross-culture perspectives on self-in-group relationships. Journal of Personality and Social Psychology, 54, 353-338.

Tu, W. M. (1985). Confucian thought: Selfhood as creative transformation. New York: State University of New York Press.

Turner, J. C., Hogg, M. A., Oakes, P. J., Reicher, S. D., \& Wetherell, M. S. (1987). Rediscovering the social group: A self-categorization theory. New York: Blackwell.

Yang, C. F. (1988). Familism and development: an examination of the role of family in contemporary Mainland China, Hong Kong, and Taiwan. In D. Sinha \& S. R. Kao (Eds.), Social values and development: Asian perspectives (pp. 93-123). New Delhi: Sage.

Yeh, K. H. (1997). Changes in the Taiwan people's concept of filial piety. In L. Y. Chang, Y. H. Lu, \& F. C. Wang (Eds.), Taiwanese society in 1990s (pp. 171-214). Taipei: Academia Sinica.

Yeh, K. H., \& Yang, K. S. (1989). Cognitive structure and development of filial piety: Concepts and measurement [in Chinese]. Bulletin of the Institute of Ethnology, 56, 131-169.

Yeh, K. H., \& Yang, K. S. (1990). An analysis of the typology of cognitive structures of filial piety [in Chinese]. In K. S. Yang \& K. K. Hwang (Eds.), Psychology and behavior of Chinese people: Proceedings of the first interdisciplinary conference (pp.141-179). Taipei: National Taiwan University, Institute of Psychology.

Yeung, S. (1989). The dynamic of family care for the elderly in Hong Kong. Unpublished doctoral dissertation. University of Hong Kong. 